\title{
BMJ Open Factors influencing trust in doctors: a community segmentation strategy for quality improvement in healthcare
}

\author{
Vijayaprasad Gopichandran, Satish Kumar Chetlapalli
}

To cite: Gopichandran V, Chetlapalli SK. Factors influencing trust in doctors: a community segmentation strategy for quality improvement in healthcare. BMJ Open 2013;3:e004115. doi:10.1136/bmjopen-2013004115

- Prepublication history for this paper is available online. To view these files please visit the journal online (http://dx.doi.org/10.1136/ bmjopen-2013-004115).

Received 25 September 2013 Revised 6 November 2013 Accepted 7 November 2013

CrossMark

School of Public Health, SRM University, Kancheepuram, Tamil Nadu, India

Correspondence to Dr Vijayaprasad Gopichandran; vijay. gopichandran@gmail.com

\begin{abstract}
Background: Trust is a forward-looking covenant between the patient and the doctor where the patient optimistically accepts his/her vulnerability. Trust is known to improve the clinical outcomes.

Objectives: To explore the factors that determine patients' trust in doctors and to segment the community based on factors which drive their trust. Setting: Resource-poor urban and rural settings in Tamil Nadu, a state in southern India.
\end{abstract}

Participants: A questionnaire was administered to a sample of 625 adult community-dwelling respondents from four districts of Tamil Nadu, India, chosen by multistage sampling strategy.

Outcome measures: The outcomes were to understand the main domains of factors influencing trust in doctors and to segment the community based on which of these domains predominantly influenced their trust.

Results: Factor analysis revealed five main categories, namely, comfort with the doctor, doctor with personal involvement with the patient, behaviourally competent doctor, doctor with a simple appearance and culturally competent doctor, which explained $49.3 \%$ of the total variance. Using $\mathrm{k}$-means cluster analysis the respondents were segmented into four groups, namely, those who have 'comfort-based trust', 'emotionally assessed trust', who were predominantly older and belonging to lower socioeconomic status, those who had 'personal trust', who were younger people from higher socioeconomic strata of the community and the group who had 'objectively assessed trust', who were younger women.

Conclusions: Trust in doctors seems to be influenced by the doctor's behaviuor, perceived comfort levels, personal involvement with the patient, and to a lesser extent by cultural competence and doctor's physical appearance. On the basis of these dimensions, the community can be segmented into distinct groups, and trust building can happen in a strategic manner which may lead to improvement in perceived quality of care.

\section{INTRODUCTION}

Trust is a major driving force for all human relationships. It is a forward looking covenant between the doctor and the patient

\section{Strengths and limitations of the study}

- This study is the first of its kind from a resourcepoor setting exploring the factors influencing trust in doctors.

- It has applied statistical methods to segment the community into groups which have different factors influencing trust.

- The scientifically rigorous and representative sampling is the strength of the study.

- The main weakness of the study is that it did not measure trust objectively and only asked a single question on whether they trust the doctor.

- Although the community segmentation strategy can be applied to other populations, the findings of this study will remain specific to this population.

where the patient believes that the doctor acts in the patient's best interest. ${ }^{1}$ It is also defined as an optimistic acceptance of vulnerability by the patient in the belief that the doctor will act with moral character and competence. $^{2}$ Trust is essential for a successful doctor-patient relationship. Several studies have shown that trust has its own benefits for the doctor and the patient. A low trust in doctor is associated with a significant psychological distress. ${ }^{3}$ A poor trust in healthcare leads to lesser health-seeking behaviour and hence poorer self-reported health status. ${ }^{4} \mathrm{~A}$ higher trust in doctor is associated with a greater care-seeking behaviour, greater adherence to the treatment regimens and better involvement of the patient in decisionmaking. ${ }^{5}$ In a study of patients with diabetes, a greater trust in doctor led to a greater selfefficacy and adherence to the treatment, thus leading to a better self-rated health status and clinical outcomes. ${ }^{6}$ In another study of trust in healthcare among patients with diabetes, higher levels of trust led to a better self-management. ${ }^{7}$ Through its interaction with self-rated health, low trust has also been shown to be associated with higher mortality rates. ${ }^{8}$ Thus, trust, apart from being 
of intrinsic value in healthcare, is also of instrumental value in bringing out favourable clinical outcomes. A high trust in doctors can be perceived as an indicator of good quality of healthcare.

There have been several studies in the developed counties about the factors influencing trust in healthcare. In a typical resource-deprived setting in Texas, a study revealed that cultural, ethnic, linguistic and social factors play a significant role in trust in healthcare. ${ }^{9}$ In a study conducted in Thailand, trust in obstetric care was influenced by perception of risk, socioeconomic status of the patient and affordability of healthcare. ${ }^{10}$ Other studies in resource-rich settings have shown that having a choice of doctors, duration of the doctor-patient relationship, higher levels of understanding, clear communication and patient friendly behaviour of the doctor increase the trust. ${ }^{11}$ Lower education, poorer social status, higher perceived risk of disease and uncertainty of clinical course have all been shown to be associated with a greater trust in the doctor. ${ }^{12}$

A qualitative study in the resource-poor setting in India showed that comfort in approaching the doctor, personal involvement of the doctor with the patient, behaviour and approach of the doctor towards the patient, economic factors and health awareness influenced the level of trust in healthcare. ${ }^{13}$ This quantitative exploration was performed to identify the factors which influence the trust of the patient on the doctor and to segment the community based on the factors that influence their level of trust. Such segmentation can be strategically used for trust building and thus improvement of perceived healthcare quality.

\section{METHODS}

\section{Study setting}

The cross-sectional study reported here was conducted in resource-poor settings in urban and rural areas in Tamil Nadu, a south Indian state. Tamil Nadu is a coastal state in the southern part of India, where it forms the lower most tip of the Indian peninsula. It is ranked sixth among the Indian states based on the Human Development Index (HDI). It has a robust public healthcare delivery system. Despite this there are pockets of poor healthcare access in the state, mainly in the fast expanding unorganised urban slums and in some geographically remote rural areas. This study was conducted in these marginalised areas, though some respondents from the mainstream society were also included.

\section{Sampling}

A sample size of 600 was calculated based on the statistical norm of 20 observations per variable in a multivariate analysis model for a total of 30 variables. ${ }^{14}$ Community-dwelling adults over 18 years of age, men and women who had sought some form of healthcare in the past, were eligible to participate in the study. Persons with severe cognitive impairment were excluded from participation. Multistage sampling strategy was used for selection of participants. Of the 32 districts in the state, four were selected by simple random sampling. For the rural sampling, one administrative block and two villages in each block were selected randomly in stages and 50 eligible respondents interviewed in each village. In the urban areas wards, census enumeration blocks and zones were selected randomly in stages and participants volunteering to respond to the study were interviewed. The last stage of selection of respondents within the clusters was non-random. There is a likelihood of significant homogeneity of trust-related variables within a cluster because of shared opinions of the community and the same doctor serving the cluster. Therefore, the non-random selection in the last stage of the sampling is unlikely to compromise the validity of the statistical analysis. Of a total 640 persons approached, a total of 625 participants were interviewed (response rate of 97.6\%) over a period of 3 months between June and August 2013. The characteristics of non-respondents were similar to those who responded to the study.

\section{Study instrument}

On the basis of findings of a qualitative study conducted in the same area, factors associated with trust in healthcare were as mentioned previously. ${ }^{13}$ Questions were developed based on these factors. The questionnaire was checked for face validity using the Delphi technique. The questions were rated on a five-point Likert scale. The questionnaire was translated into the local language Tamil and back translated to English to check for linguistic validity. The finalised questionnaire was pilot tested on a small sample. The questionnaires were administered by the author VG and three other field investigators who were trained in the interview process. Though the author VG is a physician, he does not practice in the study area and his qualification was not explicitly revealed during the interviews in order to avoid reporting bias. An information sheet about the study was given to the participants to read and take home. The details of the study were explained to them clearly. Verbal informed consent was obtained by the researcher from each participant before administering the questionnaire.

\section{Statistical methods}

The data were entered and analysed using Statistical Package for Social Sciences (SPSS) V.17. ${ }^{15}$ Factor analyses were used to identify the components of factors influencing trust in healthcare. Hierarchical cluster analysis was used to determine the number of clusters that the sample could potentially be segmented into. The factor scores were used to segment the respondents into groups by k-means cluster analysis. The characteristics of each segment were identified using descriptive analysis. 


\section{RESULTS}

Of the 625 questionnaires administered, 9 were incomplete and hence were not included in the analysis, thus leading to an effective sample size of 616. The study respondents were predominantly from rural areas and a greater proportion was women. A significant proportion of $14.4 \%$ had no formal education. About $12 \%$ were unemployed and $15 \%$ were labourers. Among the respondents, $52.5 \%$ reported some illness in the past 3 months. The characteristics of the study participants along with population characteristics of Tamil Nadu state are shown in table 1.

Responses to all the 29 statements were entered into an exploratory factor analysis model. On the basis of elbow in the scree plot, it was decided to extract a 5-component solution using a principal component extraction method. The 5-component model explained $49.3 \%$ of the total variance. The various statements relating to factors influencing trust in doctors, the proportion of the respondents who answered in affirmative for each statement and the grouping of the statements into meaningful sets of factors driving trust are shown in table 2 .

This process has meaningfully reduced the 29 statements into five sets of factors influencing trust in doctors namely comfort, personal involvement of the doctor, behavioural competence, simple and elegant appearance of the doctor and cultural competence. The analysis also gave the relative scoring of each of the respondents in each of these set of factors in the form of factor scores.

Hierarchical cluster analysis of the factors scores, using Ward linkage, showed that the respondents can be optimally classified into four clusters. The k-means cluster analysis was conducted with the regression factor scores and convergence was achieved in 12 iterations. The participants separated into four clusters whose cluster centres are shown in table 3 .

It is seen that the respondents who grouped in cluster $1 \quad(n=67)$ favoured 'comfort' and did not give importance to 'behavioural competence' or 'personal involvement of the doctor'. Cluster $2(n=133)$ members were interested in 'personal involvement of the doctor' but not in 'comfort', 'simple appearance' or 'behavioral competence'. Cluster $3(\mathrm{n}=276)$ members were particular about 'simple and elegant appearance' and 'cultural competence' dimensions whereas they were not much interested in 'personal involvement of the doctor' or 'behavioral competence'. Members of cluster $4 \quad(n=140)$ looked for 'behavioral competence' element but did not care much for 'cultural competence' or 'comfort'. The segments of the community thus obtained were labelled as 'comfort-based trust', 'personal trust', 'trust based on shared values' and 'objectively assessed trust'.

Figure 1 shows the characteristics of the respondents in each cluster. The people in the 'comfort-based trust'

Table 1 Characteristics of study participants $(n=616)$

\begin{tabular}{|c|c|c|c|}
\hline Characteristic & Categories & Frequency (\%) & $\begin{array}{l}\text { Population characteristics of } \\
\text { Tamil Nadu state }(\%)^{16-18}\end{array}$ \\
\hline \multirow[t]{6}{*}{ Age } & $18-25$ & $158(25.3)$ & 19 \\
\hline & $26-35$ & $204(32.6)$ & 16.7 \\
\hline & $36-45$ & $104(16.6)$ & 14 \\
\hline & $46-55$ & $85(13.6)$ & 10 \\
\hline & $56-65$ & $45(7.2)$ & 7 \\
\hline & $>65$ & $29(4.6)$ & 5 \\
\hline \multirow[t]{2}{*}{ Sex } & Male & $252(40.9)$ & 50.2 \\
\hline & Female & $364(59.1)$ & 49.8 \\
\hline \multirow[t]{2}{*}{ Place of residence } & Urban & $124(20.1)$ & 48.45 \\
\hline & Rural & 501 (79.9) & $51.55 \%$ \\
\hline \multirow[t]{4}{*}{ Education } & No formal education & $89(14.4)$ & Literate-73.8 \\
\hline & Schooling & $270(43.8)$ & Illiterate-26.2 \\
\hline & Graduation & $135(21.9)$ & \\
\hline & PG and professional & $122(19.8)$ & \\
\hline \multirow[t]{8}{*}{ Occupation } & Service sector & $165(26.8)$ & 22 \\
\hline & Home maker & 159 (25.9) & * \\
\hline & Laborer & $92(15)$ & 26 \\
\hline & Unemployed & $72(11.7)$ & * \\
\hline & Professional & $42(6.8)$ & 8 \\
\hline & Agricultural land owner & $38(6.2)$ & 40 \\
\hline & Business & $30(4.9)$ & 8 \\
\hline & Skilled workers & $17(2.8)$ & * \\
\hline \multirow{2}{*}{$\begin{array}{l}\text { Any sickness in the past } \\
\text { three months }\end{array}$} & Yes & $323(52.5)$ & \\
\hline & No & $292(47.5)$ & \\
\hline
\end{tabular}


Table 2 Domains of factors which influence trust in doctors

\begin{tabular}{|c|c|c|c|}
\hline Domain & Questions & $\begin{array}{l}\text { Respondents } \\
\text { who agreed (\%) }\end{array}$ & $\begin{array}{l}\text { Factor } \\
\text { loading }\end{array}$ \\
\hline \multirow[t]{8}{*}{$\begin{array}{l}\text { Behavioural } \\
\text { competence }\end{array}$} & $\begin{array}{l}\text { If the doctor explains to me clearly about the illness and its } \\
\text { treatment }\end{array}$ & 80.3 & 0.668 \\
\hline & If the doctor listens to me patiently & 79.8 & 0.666 \\
\hline & If the doctor always has a smile on his/her face & 71.5 & 0.658 \\
\hline & If the doctor is a person who always talks the truth & 75.3 & 0.633 \\
\hline & If the doctor talks to me kindly & 71.4 & 0.511 \\
\hline & $\begin{array}{l}\text { If the doctor treats everybody similarly irrespective of religion, } \\
\text { caste, language or ability to pay, etc }\end{array}$ & 74.2 & 0.510 \\
\hline & $\begin{array}{l}\text { If the doctor does not discriminate against me for reasons of } \\
\text { religion, caste, language, etc }\end{array}$ & 61.4 & 0.449 \\
\hline & If the doctor examines me with a stethoscope & 71.8 & 0.434 \\
\hline \multirow[t]{3}{*}{ Comfort } & I feel comfortable talking to him/her & 63 & 0.860 \\
\hline & I do not have any inhibitions with him/her & 539 & 0.858 \\
\hline & It is easy for me to approach the doctor & 56 & 0.779 \\
\hline \multirow[t]{8}{*}{ Personal involvement } & If the doctor recognises me and gives me special concessions & 48.8 & 0.744 \\
\hline & If the doctor knows my family situation & 55.2 & 0.701 \\
\hline & If the doctor treats me like his/her own family member & 57 & 0.661 \\
\hline & If the doctor knows me by name & 53.3 & 0.647 \\
\hline & If the doctor tries to help me beyond just my medical needs & 51 & 0.576 \\
\hline & If the doctor accepts the gifts and presents that I give & 31 & 0.549 \\
\hline & If the doctor belongs to my village/town & 51 & 0.467 \\
\hline & $\begin{array}{l}\text { If the doctor is a person who does not give much value to } \\
\text { money }\end{array}$ & 57.4 & 0.406 \\
\hline \multirow{4}{*}{$\begin{array}{l}\text { Simple \& elegant } \\
\text { appearance }\end{array}$} & If the doctor wears white or light colours clothes & 47.5 & 0.759 \\
\hline & If the doctor appears simple & 55.2 & 0.734 \\
\hline & If the doctor wears clean clothes & 66.4 & 0.722 \\
\hline & If the doctor looks elder & 52.5 & 0.566 \\
\hline \multirow[t]{4}{*}{ Cultural competence } & If the doctor belongs to my religion & 23.5 & 0.751 \\
\hline & If the doctor belongs to my caste /tribe & 22.4 & 0.743 \\
\hline & If the doctor understands my beliefs and practices & 46.1 & 0.697 \\
\hline & If the doctor speaks the same language as me & 65.6 & 0.427 \\
\hline
\end{tabular}

cluster were older, rural, women with lower education and lower levels of occupation (labourers, unemployed, etc). Those who had 'personal trust' were of younger age, higher educational attainment and better occupational levels. The segment of the community who had 'Emotional trust' was rural and had lower educational attainment. Those who had 'objectively assessed trust' seemed to be similar in profile with those who had 'personal trust' except the fact that they were predominantly younger rural women. People with personal trust were also more from urban residence compared with the other groups.

\section{DISCUSSION}

This study found that the community-perceived behavioural competence, comfort in approaching the doctor, personal involvement of the doctor, simple and elegant

Table 3 Clusters centers based on factor scores of the five domains identified

\begin{tabular}{llclc}
\hline & $\begin{array}{l}\text { Comfort-based } \\
\text { trust } \\
\mathbf{n = 6 7}\end{array}$ & $\begin{array}{l}\text { Personal } \\
\text { trust } \\
\mathbf{n = 1 3 3}\end{array}$ & $\begin{array}{l}\text { Emotionally } \\
\text { assessed trust } \\
\mathbf{n = 2 7 6}\end{array}$ & $\begin{array}{l}\text { Objectively } \\
\text { assessed trust } \\
\mathbf{n = 1 4 0}\end{array}$ \\
\hline Personal involvement of the physician & -0.35366 & $1.39398^{*}$ & $-0.58464 \dagger$ & -0.00245 \\
Behavioral competence & $-0.62375 \dagger$ & -0.31679 & -0.46689 & $1.51989^{*}$ \\
Simple and elegant appearance & 0.06329 & -0.32628 & $-0.04605^{*}$ & 0.37046 \\
Cultural competence & 0.00172 & 0.30827 & $-0.04379^{*}$ & $-0.20736 \dagger$ \\
Comfort & $2.20438^{*}$ & $-0.10570 \dagger$ & -0.53013 & 0.09058 \\
\hline
\end{tabular}

*Dimensions with maximum score.

†Dimensions with least score. 
Figure 1 The segment that trusted the doctor based on comfort was predominantly rural women of older age and were of lower educational attainment and lower occupational levels. Those who trusted based on personal involvement were younger people with higher educational attainment and occupations. Persons with lower educational levels were those who trusted based on emotional assessment. Younger women were more likely to objectively assess trustworthiness of the doctor.

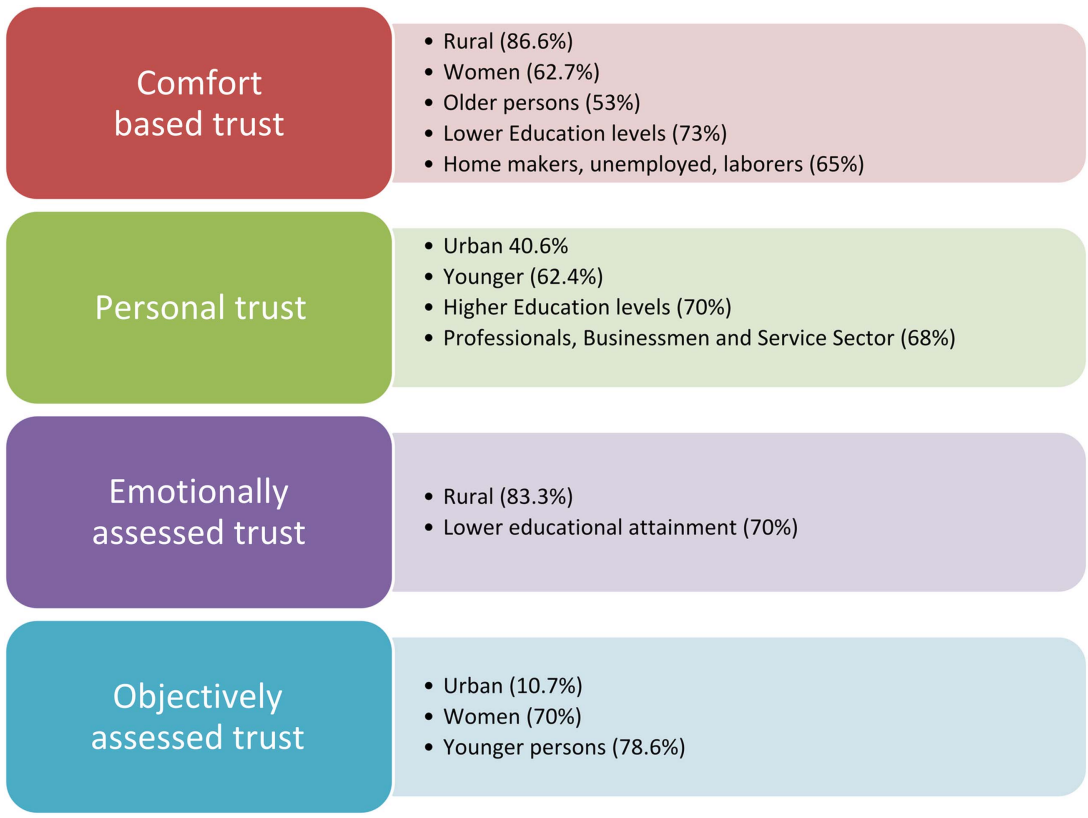

appearance and cultural competence led to increased trust in the doctor. They gave the priority to these elements of trust in the order that they have been listed above. On the basis of preference given to each of these phenomena, the participants were clustered into four segments. In the following paragraphs we discuss the four segments of the community based on the factors that influence their trust.

\section{Comfort-based trust}

This segment of the community responded that ease of approaching the doctor, not having any inhibitions and feeling comfortable talking to the doctor influenced their trust. They were not particular about the behavioural competence or personal involvement of the doctor. This segment which had $11 \%$ of all the respondents in it was characterised by the following characteristics-rural, women, older age group, belonging to lower educational and occupation status. The more marginalised segments of the society preferred comfort to other domains of factors influencing trust. The Stanford Trust Study showed that comforting and caring behaviour of the doctor led to a significant increase in trust. ${ }^{19}$ This is from the provider side of the relationship. This study reveals that the patient's perceived comfort levels also significantly influenced the level of trust in the doctor.

In India and several resource-poor settings, the doctor-patient relationship continues to have a strong shade of paternalism. Power imbalance and consumerism continues to be the norm, especially among marginalised communities living in backward areas, where education and occupation levels are lower. ${ }^{20}$ In this context, the marginalised people feel happy to have a doctor whom they can approach easily. All other factors such as behavioural competence, personal involvement of the doctor, cultural competence and appearance take a secondary stand compared with the factor 'comfort of approaching the doctor'.

A qualitative study on dimensions of trust from the same community revealed that socioeconomic considerations played an important role in influencing trust in the doctor. ${ }^{13}$ A study from a similar resource-poor setting in Thailand also showed the important role of socioeconomic status in trust. While the people who could afford it sought healthcare from private providers, the poor trusted more in the public services. ${ }^{10}$ Members of this segment who gave high importance to comfort belonged to the lower socioeconomic status. As seen in the previous studies, the socioeconomic differentials lead to a lower threshold for trust, in this case articulated as just 'comfort'.

\section{Personal trust}

Personal involvement of the doctor with the patient influenced trust for the members of this segment who comprised of $21 \%$ of the sample. These participants did not give much importance to behavioural competence, comfort, simple appearance or cultural competence. Younger individuals with higher levels of education and occupational status grouped together in the segment that trusted the doctor based on personal involvement. There was also a significantly greater composition of urban individuals in this group. This is typically the upper social stratum of the society with good access to resources and services. A qualitative study conducted on doctors showed that having a personal physician who is familiar with the patient and understands the social context and family situation of the patient would significantly increase the comfort levels and trust in healthcare. ${ }^{21}$ In another study, provision of 'personal care' was identified as a factor increasing satisfaction in healthcare. ${ }^{22}$ Satisfaction is a construct which is closely related 
to trust. ${ }^{23}$ The more educated people in the community with higher grades of occupation tend to have a better access to health services and hence have the choice of providers. This is probably a reason why they grouped into this segment, in which they clearly articulate the need for a 'personally involved' doctor. The threshold for trust seems to have risen from just comfort, to an expectation of personal involvement and personalised care in this segment. It is also possible that the people belonging to higher social strata are more skeptical in their approach to doctors and hence would prefer a 'personal doctor' to a stranger. The importance of personal involvement probably overrides the importance of all other components of trust in this segment.

\section{Emotionally assessed trust}

This segment of the sample contained $45 \%$ of the respondents. They expected that the doctor shared some common traits with them such as language, religion, caste and cultural beliefs and values. They did not give much importance to behavioural competence or personal involvement. Some of the respondents did not even give much importance to non-discrimination based on language, gender or caste, but gave more importance to emotional connectedness. About $65 \%$ of the participants thought that if the doctor spoke their own language it would lead to an increased trust. The common language apart from ease of communication also leads to a sense of social connectedness. It was observed that people who were marginalised, that is, those living in rural areas, from lower socioeconomic strata belonged to this segment. The previous studies have demonstrated the importance of language and culture in establishing good doctor-patient relationships. ${ }^{24}{ }^{25}$ The people belonging to the lower socioeconomic status also responded that they preferred doctors who dressed and appeared simple. This helped them identify with the doctor easily. While a previous study from the USA showed that patients' trust did depend on the doctor's attire, a study from Israel did not show this association. ${ }^{26} 27$ The people in the marginalised segments of the society had a more emotional and subjective assessment of trustworthiness. This is evident from the characteristics of this segment. While the 'personal trust' segment and 'objectively assessed trust' segments looked for behavioural components and personal involvement of the doctor, the members of this segment looked for emotional and social connectedness in terms of shared values.

\section{Objectively assessed trust:}

Behavioural competence was the dimension defined by the behavioural aspects of the doctor-patient relationship such as communication skills, smiling face, kindness and non-discrimination. About $22 \%$ of the sample belonged to this segment. The members of this segment were younger and predominantly women. Two important factors covered in this element reflect the core ethical character of the doctor, namely truth telling and non-discrimination.
A previous study from the USA has shown that the doctor's behaviour strongly influences trust. ${ }^{19}$ The patient friendly and patient-centered behaviours have been demonstrated to increase the trust significantly. ${ }^{28}$

This study clearly segmented the community into four categories as described above. Of these categories those who trusted based on comfort and had an emotionally assessed trust seemed to belong to marginalised segments of the society. On the other hand, those who had personal trust seemed to belong to the higher socioeconomic status. In the qualitative study from the same area, it was inferred that in resource-poor settings, the dimensions and determinants of trust are likely to be different from those in resource-rich areas. ${ }^{13}$ This study clearly demonstrates that with resource deprivation, the factors that influence trust in doctors tend to be in terms of emotional assessment rather than perceived quality of care or behavioural competence. The other explanation of this phenomenon could be that people from the better education and occupation background could articulate their expectations from the doctorpatient relationship clearly compared with those from the deprived groups.

In this study, trust was not measured objectively with any pre-existing tool or a tool developed for the local population. The entire study was based on the single question "Do factors mentioned in the following statements make you trust your doctor more?" It was assumed that all the respondents perceived trust in the same manner. Some of these factors could actually be reflecting the levels of satisfaction in care rather than trust. This has to be effectively teased out using further studies where trust and satisfaction also have to be measured using scales. It is known that trust and satisfaction are very closely related to each other, and hence the factors which influence trust are also likely to influence satisfaction. Moreover, the findings of this study are corroborated with that of the previous studies.

Some intervention studies have shown that trust in the doctor-patient relationship can be built. Interventions such as training of doctors in communication skills, transparency and financial disclosures, advertisement and display of technical qualifications of the doctor, interventions to improve universal access to healthcare, and interventions to increase the choice of affordable healthcare can all potentially increase the trust. But a Cochrane review of such interventions did not show strong evidence to support that trust can be built by any of them. ${ }^{29}$ Most of these studies are based in the USA and in other developed countries. This study throws light on the determinants of doctor-patient relationships in India. The question remains whether trust in healthcare in this setting can be built.

The segmentation of the community based on factors influencing trust can be effectively utilised to improve the perceived quality of healthcare and hence health-seeking behaviour of the community. The previous studies have shown that trust has a strong influence on health-seeking 
behaviour. Thus, targeted interventions by the healthcare providers, focusing on personal involvement with the patient, can significantly increase the trust and healthseeking behaviour among the higher socioeconomic groups. Interventions to make healthcare providers understand the importance of interaction at the emotional level can help achieve the same end in lower socioeconomic groups. The overall development of trustworthiness of the doctor in all these domains is essential, but targeted interventions with emphasis on these specific domains can be the starting stage.

The findings of this study seem to give a 'trust prescription' to the health system. It also shows that in the era of consumerism and commercialisation of healthcare, the community in resource-poor settings does project a need for revival of the 'family doctor' concept where personal involvement of the doctor can be nurtured. The study also adds that the assessment of trustworthiness at an emotional plane is quite strong in resource-poor settings and this need to be kept in mind in trust building interventions. Intervention research based on this kind of community segmentation should be conducted to examine the efficacy of this strategy. If appropriately applied, it would be a very useful tool in improving perceived quality of healthcare in resource-poor settings.

Acknowledgements The authors acknowledge the intellectual contributions of Professor M Bhagavandas, Professor of Biostatistics, School of Public Health.

Contributors VG conceptualised the study, designed the study, conducted the literature review, collected data, analysed and interpreted the data, wrote the manuscript and approved the final draft. SKC conceptualised and participated in the design of study, participated in data interpretation, edited the manuscript and approved the final draft.

Funding This research received no specific grant from any funding agency in the public, commercial or not-for-profit sectors.

Competing interests VG is supported by the INSPIRE Fellowship of the Department of Science and Technology, Government of India.

Ethics approval The study was reviewed in the Institutional Review Board and Ethics Committee of School of Public Health, SRM University and it was given approval. This informed consent process was approved by the ethics committee.

Provenance and peer review Not commissioned; externally peer reviewed.

Data sharing statement No additional data are available.

Open Access This is an Open Access article distributed in accordance with the Creative Commons Attribution Non Commercial (CC BY-NC 3.0) license, which permits others to distribute, remix, adapt, build upon this work noncommercially, and license their derivative works on different terms, provided the original work is properly cited and the use is non-commercial. See: http:// creativecommons.org/licenses/by-nc/3.0/

\section{REFERENCES}

1. Hall MA, Dugan $E$, Zheng $B$, et al. Trust in physicians and medical institutions: what is it, can it be measured, and does it matter? Milbank Q 2001;79:613-39.
2. Fugelli P. James Mackenzie lecture. Trust—in general practice. $\mathrm{Br} \mathrm{J}$ Gen Pract 2001;51:575.

3. Ahnquist J, Wamala SP, Lindstrom M. What has trust in the health-care system got to do with psychological distress? Analyses from the national Swedish survey of public health. Int $J$ Qual Health C 2010;22:250-8.

4. Mohseni M, Lindstrom M. Social capital, trust in the health-care system and self-rated health: the role of access to health care in a population-based study. Soc Sci Med 2007;64:1373-83.

5. Trachtenberg F, Dugan E, Hall MA. How patients trust relates to their involvement in medical care. J Fam Pract 2005;54:344-52.

6. Lee YY, Lin JL. The effects of trust in physician on self-efficacy, adherence and diabetes outcomes. Soc Sci Med 2009;68:1060-8.

7. Bonds D, Camacho F, Bell R, et al. The association of patient trust and self-care among patients with diabetes mellitus. BMC Fam Pract 2004;5:26

8. Nummela O, Raivio R, Uutela A. Trust, self-rated health and mortality: a longitudinal study among ageing people in Southern Finland. Soc Sci Med 2012;74:1639-43.

9. Franzini L. Self-rated health and trust in low-income Mexican-origin individuals in Texas. Soc Sci Med 2008;67:1959-69.

10. Riewpaiboon W, Chuengsatiansup K, Gilson L, et al. Private obstetric practice in a public hospital: mythical trust in obstetric care. Soc Sci Med 2005;61:1408-17.

11. Kao AC, Green DC, Zaslavsky AM, et al. The relationship between method of physician payment and patient trust. JAMA 1998;280:1708-14.

12. Kayaniyil S, Gravely Witte S, Stewart DE, et al. Degree and correlates of patient trust in their cardiologist. J Eval Clin Pract 2009;15:634-40.

13. Gopichandran V, Chetlapalli SK. Dimensions and determinants of trust in health care in resource poor settings-a qualitative exploration. PLOS ONE 2013;8:e69170.

14. Beavers AS, Lounsbury JW, Richards JK, et al. Practical considerations for using exploratory factor analysis in educational research. Pract Assesst, Res Eval 2013;18:2.

15. SPSS Inc. SPSS Statistics for Windows Version 17.0 [computer program]. 2008

16. Navaneetham K, Dharmalingam A. Demography and development: preliminary interpretations of the 2011 census. Econ Polit Wkly 2011:46:13.

17. Dyson T. The preliminary demography of the 2001 census of India Popul Dev Rev 2001;27:341-56.

18. Chowdhury S. Employment in India: What does the latest data show? Econ Polit Wkly 2011;46:23-6.

19. Thom DH. Physician behaviors that predict patient trust. $J$ Fam Pract 2001:50:323-8.

20. Fochsen G, Deshpande K, Thorson A. Power imbalance and consumerism in the doctor-patient relationship: health care providers GÇÖ experiences of patient encounters in a rural district in India. Qual Health Res 2006;16:1236-51.

21. DeVoe JE, Nordin T, Kelly K, et al. Having and being a personal physician: vision of the Pisacano scholars. J Am Board Fam Med 2011;24:463-8.

22. Cleary PD, McNeil BJ. Patient satisfaction as an indicator of quality care. Inquiry 1988;25:25-36.

23. Platonova EA, Kennedy KN, Shewchuk RM. Understanding patient satisfaction, trust and loyalty to primary care physicians. Med Care Res Rev 2008;65:696-712.

24. Ferguson WJ, Candib LM. Culture, language and the doctor-patient relationship. Fam Med 2002;34:353-61.

25. Hughes K. Doctors developing patient trust. NZFP 2003;30:336-41.

26. Rehman SU, Nietert PJ, Cope DW, et al. What to wear today? Effect of doctor's attire on the trust and confidence of patients. Am J Med 2005;118:1279-86.

27. Menahem S, Shvartzman P. Is our appearance important to our patients? Fam Pract 1998;15:391-7.

28. Fiscella $\mathrm{K}$, Meldrum S, Franks $\mathrm{P}$, et al. Patient trust: is it related to patient-centered behavior of primary care physicians? Med Care 2004;42:1049

29. McKinstry B, Ashcroft RE, Car J, et al. Interventions for improving patients' trust in doctors and groups of doctors. Cochrane Database Syst Rev 2006;(3):CD004134. 